DIW BERLIN

Discussion

Papers
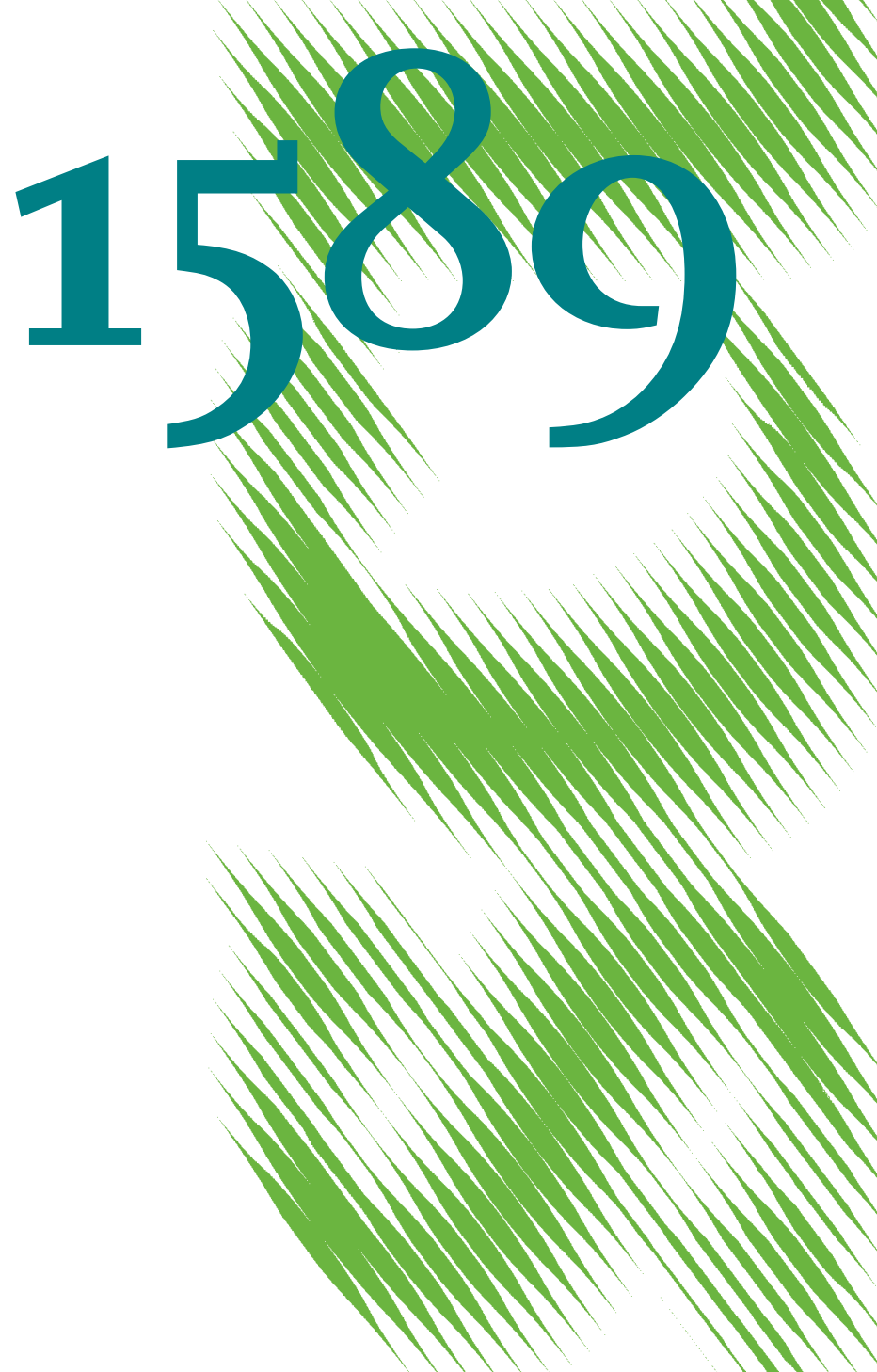

Intended College Enrollment and Educational Inequality:

Do Students Lack Information? 
Opinions expressed in this paper are those of the author(s) and do not necessarily reflect views of the institute.

IMPRESSUM

(C) DIW Berlin, 2016

DIW Berlin

German Institute for Economic Research

Mohrenstr. 58

10117 Berlin

Tel. +49 (30) $89789-0$

Fax +49 (30) $89789-200$

http://www.diw.de

ISSN electronic edition 1619-4535

Papers can be downloaded free of charge from the DIW Berlin website:

http://www.diw.de/discussionpapers

Discussion Papers of DIW Berlin are indexed in RePEc and SSRN:

http://ideas.repec.org/s/diw/diwwpp.html

http://www.ssrn.com/link/DIW-Berlin-German-Inst-Econ-Res.html 


\title{
Intended College Enrollment and Educational Inequality: Do Students Lack Information?
}

\author{
Frauke H. Peter, Vaishali Zambre*
}

May 10, 2016

\begin{abstract}
Despite increasing access to university education, students from disadvantaged or non-academic family backgrounds are still underrepresented at universities. In this regard, the economic literature mainly studies the effect of financial constraints on post-secondary educational decisions. Our knowledge on potential effects of other constraints regarding university education is more limited. We investigate the causal relationship between information and educational expectations using data from a German randomized controlled trial in which students in high schools were treated with information on the benefits as well as on different funding possibilities for university education. We find that the provision of information increases intended college enrollment for students from a non-academic family background, while it leads students from academic backgrounds to lower their enrollment intentions. Our results suggest that educational inequality can be reduced by providing students with relevant information, while simultaneously improving post-secondary education matches.
\end{abstract}

Keywords: Randomized Controlled Trial, Information Deficit, Educational Expectation, College Enrollment, Educational Inequality

JEL: I21, I24, J24

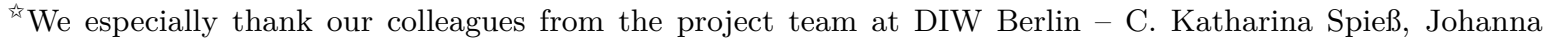
Storck, and Mathias Huebener; and at WZB - Heike Solga, Alessandra Rusconi, Claudia Finger, and Martin Ehlert. Moreover, we thank Susan Dynarski, Brian McCall and Astrid Würtz Rasmussen as well as participants of the 6th IWAEE conference, the 4th SOLE/EALE world conference, the 2015 EEA Annual Congress and the 2016 AEA Annual Meeting for valuable comments. We gratefully acknowledge funding from the Einstein Foundation Berlin (A-2010-025 (FU)). The usual disclaimer applies.

${ }^{*}$ Corresponding author

Email addresses: fpeter@diw.de (Frauke H. Peter), vzambre@diw.de (Vaishali Zambre)
} 


\section{Introduction}

Around the world, post-secondary educational decisions consistently depend on individuals' socio-economic background. In Germany, the odds of starting university education is 37 percent for students from non-academic backgrounds, but the odds are 84 percent for students from academic backgrounds (Middendorff, Apolinarski, Poskowsky, Kandulla, and Netz, 2013). In the economic literature, these observed differences in educational choices have been mainly examined as an effect of financial constraints. This focus stems partly from the fact that most studies are based on English-speaking countries where tuition fees indeed present a high financial burden. In countries like Germany, however, university education is free of charge ${ }^{1}$ and the government provides means-tested financial support to finance living expenses. Financial constraints are, thus, less likely to explain the observed differences in enrollment rates. The results of Steiner and Wrohlich (2012) support this argument, as they find only a small elasticity of student aid (BAföG) on participation in tertiary education in Germany. ${ }^{2}$

A relatively new explanation for the differing decisions to study based on socio-economic background is a potential lack of information. Given that educational choices are usually modeled as the result of cost-benefit considerations, it is essential that students know about costs and benefits of university education and how they compare to alternative choices. Acknowledging the uncertainty involved in educational choices, where the odds of success and the subsequent returns are uncertain, students must base their decision on the information available to them and form expectations. These expectations are, in turn, shaped by the socio-economic environment of students (Manski, 1993a b; Bifulco, Fletcher, Oh, and Ross, 2014). Consequently, expectations and information sets may differ by students' educational backgrounds.3 ${ }^{3}$ Different information sets at the time of the decision making may explain why students from different educational backgrounds arrive at different educational choices. Thus, directly providing information may help students to make a more informed and background independent decision.

In this paper we investigate how students' intended college enrollment changes as a result of extending their information set. We use data from a randomized controlled trial in Germany in which high school students one year prior to their graduation exams were provided with information about returns to and funding possibilities of post-secondary education. During this in-class information intervention labor market benefits of university education were compared to vocational training. This presentation was given using a standardized script in order to ensure that information was consistently presented across the random sample of high schools.

A growing number of studies investigate the relationship between information and educational choices. Some studies provide information about costs and benefits of education (Oreopoulos and Dunn, 2013; McGuigan, McNally, and Wyness, 2014; Kerr, Pekkarinen, Sarvimäki, and Uusitalo, 2015), while other studies focus on specific information, i.e. provide students solely with information on financing possibilities (Booij, Leuven, and Oosterbeek, 2012, Herber,

\footnotetext{
${ }^{1}$ In 2006, seven out of sixteen states in Germany introduced tuition fees, which triggered a lively discussion about fairness in access to university education. However, by 2014 all states had abolished tuition fees.

${ }^{2}$ Even in the English-speaking world the effect of financial aid programs is mixed (for an overview see Dynarski $(2002)$ ).

${ }^{3}$ As pointed out by Oxoby (2008), students also infer their own ability from observations of similar individuals, who successfully took the same path.
} 
2015 ) or examine the effect of information on the application process for college and financial aid (Bettinger, Long, Oreopoulos, and Sanbonmatsu, 2012; Hoxby and Turner, 2014). Furthermore, there are studies exploring the influence of (general) information on educational decision-making in developing countries (Nguyen, 2008; Loyalka, Song, Wei, Zhong, and Rozelle, 2013, Jensen, 2010, Dinkelman and Martínez, 2014), where the lack of information may be even more severe as obtaining information is more difficult.

The existing evidence shows that providing information improves students' knowledge. As we would expect, these improvements are larger for students from disadvantaged backgrounds indicating that ex ante students might underestimate the returns to post-secondary education or their probabilities of succeeding in higher education. Yet, it is still unclear under which circumstances and in which context the provision of information impacts educational choices. The type of information, the mode of presenting information as well as the duration and the level of interaction varies greatly across existing studies. Correspondingly, results are mixed, allowing neither the conclusion that information does impact educational choices nor that it does not. Further, most of the evidence refers to countries with comparatively high tuition fees. In these countries the extent to which information can affect educational decisions may be restricted as financial constraints might likely be more important than a lack of information. Hence, looking at data from a German randomized controlled trial may shed further light on the effectiveness of information provision in a tuition free context.

Our study shares similarities with the information treatments assessed by Oreopoulos and Dunn (2013); McGuigan, McNally, and Wyness (2014) and Kerr, Pekkarinen, Sarvimäki, and Uusitalo (2015). Oreopoulos and Dunn (2013) investigate the effect of an Internet based information campaign for high school students from disadvantaged schools in Toronto. The authors examine the effect of this information treatment on students' belief about the returns and costs of higher education as well as on their aspiration to earn a college degree. They find providing information to be effective for students who initially stated that they were unsure about their desired educational attainment. However, Oreopoulos and Dunn (2013) find no change in the intention of students who do not plan seek further education following high school. The paper by McGuigan, McNally, and Wyness (2014) examines students aged 14 or 15 in a sample of London schools. Their results show that information provision has an effect on staying in education, i.e. students continue to obtain their A-levels, but the authors find no effect on the intention to go to college. These two studies were conducted in countries where students need to pay tuition and their results may not extrapolate to countries where financial constraints should be of less importance. To the best of our knowledge, the study by Kerr, Pekkarinen, Sarvimäki, and Uusitalo (2015) is the only other study providing information on the costs and benefits of university education in a tuition free country. Kerr, Pekkarinen, Sarvimäki, and Uusitalo (2015) focus on students' choice of major in Finland treating students close to graduation with major-specific information. They find no significant effect on major-specific applications or enrollment rates. The authors conclude that a potential lack of information on labor market success may not be important for educational choices.

We add to the existing literature by analyzing the differential effects of providing information on intended college enrollment by students' educational background. We assess a treatment 
effect two to three months after provision of information. Our results show that the information treatment affects intended college enrollment. For students from a non-academic family background intended college enrollment increases by 8 percentage points, while students from academic backgrounds decrease their enrollment intention by 5 percentage points. This suggests that increasing information indeed narrows the gap in intended college enrollment by educational background. Examining the effect of information on intended college enrollment instead of the actual transition is sometimes viewed as a drawback, neglecting the fact that actual transition is critically influenced by university entry restrictions. As such, focusing on intentions can yield valuable insights on the effectiveness of providing information as it abstracts from supply side restrictions of university education. Meaning that intended college enrollment measures students' individual preferences for tertiary education that are not dependent on the number of places available at universities or enrollment restrictions based on grade point averages. 4

The remainder of the paper is structured as follows: Section 2 describes the institutional context in Germany. Section 3 describes the randomized controlled trial, the intervention as well as the data. Section 4 introduces the empirical strategy and in Section 5 we report our estimation results. In Section 6 we present some robustness tests before Section 7 discusses our findings and concludes.

\section{Institutional context}

In Germany education policy is the responsibility of each federal state (Bundesland). Thus, education systems differ across the sixteen states. The data used in this paper stems from a randomized controlled trial conducted in the federal state of Berlin, where students complete six years of primary schoo 5 before being assigned to different tracks of secondary schooling according to their ability. Secondary school tracks can be differentiated into a vocational and a university track $6^{6}$ Only at university track schools can students earn the general university entrance diploma, which in Germany is called Abitur, that allows students to immediately start university following graduation. In our study, we exclusively focus on students working toward the Abitur degree; excluding those striving for other specialized high school diplomas. In Berlin students can earn their Abitur at 137 schools. These 137 schools are divided into three school types: (1) general high schools (Gymnasium); (2) comprehensive high schools (integrierte Sekundarschule); and (3) vocational oriented high schools (berufliches Gymnasium).

Post-secondary educational decisions in Germany differ from other countries. After earning the Abitur almost all students stay in post-secondary education, with a very small share deciding not to seek any further education. Consequently, students usually decide between university or vocational education. The German vocational education system constitutes an attractive alternative to university education, as it is a highly recognized dual system that offers

\footnotetext{
${ }^{4}$ Moreover, based on psychological theory, intentions are a precondition for behavior, describing an individual's intention to induce actual behavior (Ajzen, 1991, 1985, Fishbein and Ajzen, 1975).

${ }^{5}$ The transition to secondary schooling after six years occurs in three federal states (Berlin, Brandenburg, and Mecklenburg-West Pomerania); in all other federal states children start secondary school following the completion of grade four.

${ }^{6}$ We subsume Hauptschule and Realschule as vocational track schools and Gymnasium and gymnasiale Oberstufe as university track schools.
} 
good employment prospects. Although primarily designed for students with a lower or middle secondary schooling degree, a range of vocational apprenticeship programs require the Abitur and, in addition, the probability of admission to white collar vocational programs is very low without the Abitur. Approximately a quarter of students earning the Abitur choose a vocational education (Bildungsberichterstattung (2014):107). The number of students pursuing an apprenticeship after obtaining the Abitur has increased over the last years, as particularly white collar jobs, i.e. banker, (insurance) salesman, etc., now require good upper-secondary degrees (Abitur). Thus, students who would have left school with a good middle secondary schooling degree might decide to pursue the university entrance degree only to enter profitable vocational education programs. If policy makers aim to increase general enrollment rates in university, targeting this group may be most effective because these students are already equipped with the necessary academic performance.

Furthermore, students from low educational backgrounds decide more often to pursue vocational education than their peers from an academic family background. Conditional on earning the Abitur, the transition probability to university education is between 10 and 20 percentage points lower for students with lower educated parents Given the ability tracking after primary school and the associated selectivity of students who earn the Abitur, the observed differences in post-secondary decisions by students' educational background is a source of concern. If the inequalities at earlier stages are taken into account, the odds of starting university education is more than twice as high for students from academic compared to non-academic family backgrounds (84\% vs. 37\%) (Middendorff, Apolinarski, Poskowsky, Kandulla, and Netz, 2013). One clear benefit of vocational education in the dual system is its remuneration, which renders students independent of other financial sources. Some authors argue that having a vocational education system that offers students an attractive alternative to university education, may partly explain why students from low educational backgrounds are underrepresented at German universities (Becker and Hecken, 2008). In particular since at labor market entry the earnings differential between university graduates is not very high compared to those that graduate from vocational training as bankers or the like.

\section{Randomized controlled trial}

In this section the set up of the randomized controlled trial (RCT hereafter) and the data used are described in more detail. The information intervention was conducted as part of a larger project called Berliner-Studienberechtigten-Panel (Best Up).7 In this project some high schools in Berlin were randomly treated with an in-class presentation providing information on returns to university education as well as on potential financing strategies.

"Best Up" project setup. The aim of the project was to obtain a target sample of 27 schools (20\% of all upper secondary schools in Berlin) that have a large share of students from

\footnotetext{
${ }^{7}$ The project is a co-operation between the German Institute for Economic Research (DIW) and the Berlin Social Science Center (WZB). The Best Up project is funded by the Einstein Foundation Berlin. For further information on the project see: http://www.diw.de/en/diw_01.c.409542.en.
} 
non-academic family backgrounds. High schools without intakes in fifth grade ${ }^{8}$ were stratified using (1) school type; (2) share of population aged 25 and older with low education (ISCED 0-2) per district; (3) cohort size one year prior the Abitur exams; (4) share of students with migration background; and (5) share of female students as stratifying variables. With the exception of the share of low educated individuals within the district, all variables are measured at the school level. By including district-level information to draw the school sample, the Best Up project setup aimed at oversampling students from lower educated backgrounds. Based on the results of the stratification, a set of potential schools was identified that was similar in terms of the stratifying variables. Stratification was implemented using coarsened exact matching (CEM) as proposed by Iacus, King, and Porro (2009).9

Schools were subsequently contacted and asked whether they would like to participate in a survey aiming to gain knowledge on how students can be better supported in choosing their post-secondary educational path. After schools had agreed to participate, schools within school types were randomly assigned into treatment and control group. The final sample of Best Up consists of 9 treatment and 18 control schools. After allocating schools into treatment and control group, headmasters were contacted again to schedule a date for the survey. Treatment schools were asked for an additional hour to accommodate the information workshop. A few weeks before the survey, an invitation to participate in the survey was distributed among all students who were on track to take Abitur exams the following year.

Information intervention. The information workshop was composed of a 20-minute inclass presentation on returns to post-secondary education as well as on different funding possibilities of university education. The information workshop was not designed to advertise university education but rather to provide students with information relevant to making a more informed decision. In contrast to the studies by McGuigan, McNally, and Wyness (2014) and Kerr, Pekkarinen, Sarvimäki, and Uusitalo (2015)), the presentation was given by a trained person with a concise script from the RCT team, which ensures a more consistent treatment than providing schools or student counselors with information materials, who may present the material with their own interpretation and/or selection of information. Another component of the information treatment was a 3-minute video at the end of the intervention summarizing the provided information of the presentation thereby guaranteeing standardization of treatment.

The information on labor market returns comprised visualized information on earnings differences, career perspectives, unemployment risk and the gain in life-time earnings. Students received "tailored information," meaning information relevant for students with Abitur. The general numbers available on differences in earnings do not differentiate by highest achieved schooling degree. While Abitur is a prerequisite for university enrollment, most vocational degrees can also be obtained with a lower schooling degree. Consequently, the returns to a vocational degree largely depend on the highest achieved schooling degree ${ }^{10}$ Thus, during the

\footnotetext{
${ }^{8}$ Out of the 137 Berlin high schools, 33 schools which admit high ability students in grade five are excluded from the target population, since students with a non-academic background are likely to be underrepresented in these schools.

${ }^{9}$ Stratification was only used to draw the school sample and played no role in randomization.

${ }^{10}$ Students holding a lower secondary schooling degree do not qualify for all vocational education programs.
} 
information workshop, labor market benefits of university education were compared to vocational education conditional on having earned the Abitur. It also pointed toward gender differences in earnings and differences across fields of study.

With respect to the possibilities to finance university studies, the main sources of funding in Germany - BAföG (student aid), scholarships and students jobs - were introduced. The information on student aid also included basic information about repayment conditions, stressing that only half of the amount received as student aid must be repaid and repayment obligations only start once earnings exceed a certain threshold.

The information on direct costs of university education emphasized that no tuition fees need to be paid (anymore) and, consequently, monthly average costs equal living expenses, which have to be financed irrespective of the educational path taken. Hence, the costs of university education boil down to the opportunity costs, which correspond to the remuneration of vocational trainees. Most of the information was visualized in order to make the information more accessible to students.

In order to verify whether the information workshop successfully conveyed information to students, we compare perceived labor market benefits of university education pre- and posttreatment. As labor market benefits we consider the subjective unemployment risk, the subjective prospects of finding a well-paid job, and the subjective income premium of university education. We are only able to assess a small subset of subjective beliefs of labor market returns. The information treatment, however, consisted of a bundle of information on post-secondary education among which labor market returns were just one aspect. With respect to beliefs about funding possibilities, we lack appropriate data. Our estimates suggest that students absorbed the provided information, as they updated their subjective beliefs in the expected way and all estimates have the expected sign and are, despite one exception, statistically significant. Students in the treatment group are significantly more likely to expect their unemployment risk to be smaller and their prospects of finding a well-paid job to be higher with a university degree than with a vocational degree 11 As such, the information workshop seems to have provided students with new and relevant information that may influence their educational decision making.

Data. We use data from the first two Best Up surveys conducted pre- and post-treatment. The pre-treatment survey was administered in schools one year prior to the Abitur exams using a paper-based questionnaire. It was executed in schools under exam conditions. Teachers were only present to provide their obligatory supervision. In treated schools the survey directly preceded the information provision. A total of 1578 students participated in the first survey Approximately two to three months later a follow-up online survey was carried out. The response rate for the second survey (post-treatment) was 70\%, which is higher than in comparable studies (see e.g. Booij, Leuven, and Oosterbeek, 2012, Oreopoulos and Dunn, 2013). More importantly, the response rate is virtually identical between the treatment $(69.72 \%)$ and control group $(70.17 \%)$. Yet, to obtain an unbiased estimator of the treatment effect it is important that intended college enrollment and background characteristics do not influence drop out be-

\footnotetext{
${ }^{11}$ See Table A.2 in the appendix.

${ }^{12}$ Taking the full cohort of each school as a reference, this corresponds to an overall response rate of $60 \%$.
} 
havior differently by treatment status. Based on a Chow-test, we do not find any evidence for differential attrition 13

Analyzed sample. We restrict our analysis sample to students participating in both the pre- and post-treatment surveys. Further, we keep only students with information on pre- and post-treatment enrollment intention as well as information on educational background. Intended college enrollment is measured by asking students which education they plan to pursue after earning their Abitur ${ }^{14}$ Students can choose between university education (at different types of universities $[15$, vocational education, or no education. We define intended college enrollment as a binary variable, such that it equals one if the student intends to go to university and zero otherwise. The vast majority of students who do not intend to enroll, plan to pursue a vocational education ${ }^{16}$ The final sample for analysis comprises 988 observations. Missing information on the key variables does not differ significantly between treatment and control group. We define educational background to be either academic or non-academic. Meaning students' are from a non-academic family background if no parent (genetic or social) holds a university degree, or from an academic family background if at least one parent holds a university degree. For students who did not answer the questions addressing both parents' education, we made the following assumption to determine their educational background: Students either stating that they do not know their mother or father or students with missing information on the level of education of one parent were classified according to the valid information on the one (the other) parent.17 In specifications where we control for additional covariates, we deal with missing information by setting these variables to a constant value and including a dichotomous variable indicating missing covariates 18

Covariate balance. We test whether randomization was successful by comparing the balance of covariates between treatment and control group. As is common in RCTs in the field of education, schools instead of individuals were randomized to best mimic a potential policy measure and avoid spill over effects within schools. As we are interested in the differential effect by educational background, we examine treatment effects at the individual level. However, the composition of students within schools is usually non-random, such that the probability of balancing covariates at the individual level is lower if entire schools instead of individuals are randomized. We assess randomization in the sample that we use for our analysis, as well as for the subgroups

\footnotetext{
${ }^{13}$ Tested covariates comprise age, gender, migration background, non-academic family background, school types, enrollment intention, math and German grades as well as two measures of cognitive skills; $F_{(12,1545)}=0.86, p-$ value $=0.5924$.

${ }^{14}$ The translated survey question reads: Think of everything you know today: Which type of education will you most likely pursue after graduating from high school?

${ }^{15}$ The institutions comprise universities, universities of applied sciences, field specific universities, and vocational oriented universities.

${ }^{16}$ Only around two (one) percent of the students who participated in the pre-treatment (post-treatment) survey plan to obtain no further education.

${ }^{17}$ If information on parental education is completely missing, we use the education of older siblings to proxy educational background.

${ }^{18}$ Estimating the treatment effect using only students with non-missing information on all covariates, does not change our conclusions. Results are available upon request
} 
by educational background 19 Table 1 displays the covariate balance by treatment status and indicates that randomization balanced most of the covariates. The only exception is scores on the figural cognition test in the subsample of students from academic backgrounds. Students in the treatment group show slightly higher scores. However, the absolute size of the difference corresponds to a fifth of a standard deviation, which we consider negligible. Conducting F-tests we are able to accept the null hypothesis that in a regression of individual characteristics and measures of performance and skills (as listed in Table 1) on treatment status, these variables are jointly equal to zero in all three samples 20

Table 1: Covariate balance by treatment status

\begin{tabular}{|c|c|c|c|c|c|c|}
\hline & \multicolumn{2}{|c|}{ Analyzed sample } & \multicolumn{2}{|c|}{ Non-academics } & \multicolumn{2}{|c|}{ Academics } \\
\hline & $\begin{array}{c}\text { Control } \\
\text { Group Mean }\end{array}$ & $\begin{array}{c}\text { Treatment } \\
\text { Group Diff. }\end{array}$ & $\begin{array}{c}\text { Control } \\
\text { Group Mean }\end{array}$ & $\begin{array}{l}\text { Treatment } \\
\text { Group Diff. }\end{array}$ & $\begin{array}{c}\text { Control } \\
\text { Group Mean }\end{array}$ & $\begin{array}{l}\text { Treatment } \\
\text { Group Diff. }\end{array}$ \\
\hline \multicolumn{7}{|l|}{ Individual characteristics } \\
\hline Age & 18.559 & -0.033 & 18.722 & -0.191 & 18.295 & 0.223 \\
\hline Female & 0.588 & 0.013 & 0.601 & 0.050 & 0.567 & -0.050 \\
\hline Migration background & 0.461 & 0.070 & 0.502 & 0.064 & 0.395 & 0.078 \\
\hline Non-academic fam.backgr. & 0.617 & 0.010 & & & & \\
\hline \multicolumn{7}{|l|}{ Performance and skills } \\
\hline German Grade & 8.797 & -0.235 & 8.468 & -0.005 & 9.323 & -0.593 \\
\hline Math Grade & 8.083 & 0.212 & 7.896 & 0.220 & 8.384 & 0.220 \\
\hline Cognition test (verbal) & 9.827 & 0.219 & 9.425 & 0.111 & 10.475 & 0.428 \\
\hline Cognition test (figural) & 11.044 & 0.074 & 10.772 & 0.462 & 11.483 & $-0.562^{*}$ \\
\hline \multicolumn{7}{|l|}{ School type } \\
\hline School type I (Gym.) & 0.331 & -0.080 & 0.290 & 0.018 & 0.398 & -0.241 \\
\hline School type II (Gesamtschule) & 0.355 & 0.050 & 0.371 & 0.010 & 0.330 & 0.118 \\
\hline School typ III (berufl.Gym.) & 0.314 & 0.029 & 0.340 & -0.027 & 0.272 & 0.123 \\
\hline \multicolumn{7}{|l|}{ Perceived returns } \\
\hline Unemp.risk smaller & 0.407 & -0.019 & 0.385 & 0.000 & 0.443 & -0.050 \\
\hline Prosp. for well paid job higher & 0.713 & 0.000 & 0.712 & 0.017 & 0.715 & -0.027 \\
\hline Rel.inc.premium (B.A./Voc.degr.) & 1.531 & -0.042 & 1.545 & -0.039 & 1.507 & -0.047 \\
\hline Life time inc. higher & 0.646 & 0.001 & 0.668 & -0.060 & 0.610 & $0.102^{*}$ \\
\hline $\mathrm{N}$ & 682 & 306 & 421 & 192 & 261 & 114 \\
\hline $\mathrm{N}$ (total) & \multicolumn{2}{|c|}{988} & \multicolumn{2}{|c|}{613} & \multicolumn{2}{|c|}{375} \\
\hline
\end{tabular}

Notes: This table presents control group means and treatment-control differences based on a two-sided t-test. Standard errors are clustered at the school level. Source: Best Up, wave 1. ${ }^{*} p<0.1,{ }^{* *} p<0.05,{ }^{* * *} p<0.01$.

\section{Empirical framework}

When analyzing data from a RCT it is generally sufficient to compare the average posttreatment outcomes by treatment status to identify the causal effect of the treatment. Randomization ensures that the estimates do not suffer from selection into treatment. However, based on the information of the pre-treatment survey, we see that (conditional on the sample used for our analysis) pre-treatment intentions to enroll in college are already 4.5 percentage points lower in the treatment than in the control group. If we look at the subsample of students with a non-academic background this difference is even 5.8 percentage points (see Table 1) ${ }^{21}$

\footnotetext{
${ }^{19}$ For covariate balance checks in the full sample, see Table A.1 in the Appendix

${ }^{20}$ Corresponding p-values of the F-tests are: in the analyzed sample 0.3822 ; in the sample of non-academics 0.3778; and in the sample of academics 0.3453. F-test are based on regressions with standard errors clustered at the school level.

${ }^{21}$ The difference in pre-treatment intended college enrollment between treated and untreated students from academic backgrounds is with 1.9 percentage points far less of a concern.
} 
As our core interest lies in the effect of the information intervention on intended college enrollment for students from non-academic backgrounds, it is unfortunate that randomization did not render intended college enrollment entirely balanced by treatment status. Although these differences are insignificant, the size of the difference cannot be ignored. If, for example, the true effect of the information intervention for students from a non-academic family background is less than 5.8 percentage points, by only comparing post-treatment outcomes we were to conclude that the information intervention had no effect on intended college enrollment. And even if the true effect is larger than 5.8 percentage points, we would still highly underestimate the treatment effect for students from a non-academic family background - the group of major interest in our study.

Thus, to obtain a causal effect of providing information we compare post-treatment intended college enrollment by treatment status and control for students' pre-treatment intention. We estimate the following equation for the whole sample as well as separately for students from a non-academic and academic family background:

$$
y_{i s}^{\left(t_{1}\right)}=\alpha+\beta_{1} T_{s}+\beta_{2} y_{i s}^{\left(t_{0}\right)}+X_{i}^{\prime} \beta_{3}+\epsilon_{i s}
$$

where $y_{i s}^{\left(t_{1}\right)}$ equals 1 if student $i$ in school $s$ intends to enroll in college in $t_{1}$, i.e. the post-treatment period and 0 otherwise. $T_{s}$ is the treatment group indicator and $y_{i s}^{\left(t_{0}\right)}$ a binary variable indicating student $i^{\prime} s$ pre-treatment intended college enrollment. We add $X_{i}$, a vector of additional pretreatment individual level controls, including age, gender, migration background, school type, standardized pre-treatment math and German grades as well as cognitive skills measured by a verbal and a matrix test, in order to increase precision of our estimates. The error term $\varepsilon_{i s}$ captures the remaining variation. To account for potential dependence of observations within schools we cluster standard errors at the school level. $\beta_{1}$ is the coefficient of interest and identifies the effect of the information treatment.

This approach, however, cannot completely resolve the pre-treatment difference in intended college enrollment as it only adjusts the estimates for a fraction of these differences, i.e. the coefficient $\beta_{2}$ in Equation 1 will usually be less than one Allison, 1990). Therefore, we compare the change in students' intended college enrollment by treatment status as our preferred specification, i.e. estimate the following equation: .

$$
\Delta y=y_{i s}^{\left(t_{1}\right)}-y_{i s}^{\left(t_{0}\right)}=\alpha+\beta_{1} T_{s}+X_{i}^{\prime} \beta_{2}+\epsilon_{i s}
$$

where $y_{i s}$ is the intended college enrollment of student $i$ in school $s$ at time $t_{0}$ or $t_{1}$, i.e. before or after the treatment. Again, $T_{s}$ is the treatment group indicator and $X_{i}$ is a vector of individual level controls 22 The error term $\epsilon_{i s}$ is clustered at the school level.

By using the difference between pre- and post-treatment intended college enrollment as our main outcome, we not only fully account for the pre-treatment imbalance in enrollment intentions but also for any time invariant observables and unobservables that might influence (potential) enrollment intention and are different by treatment status.

\footnotetext{
${ }^{22}$ Additional controls include, as before, age, gender, migration background, school type, standardized pretreatment math and German grades as well as two measures of cognitive skills.
} 


\section{Results}

\subsection{Pre-treatment survey evidence}

Before we present the effect of the information workshop on students' intended college enrollment, we show descriptive evidence on the lack and relevance of information using pre-treatment data. In a first step we investigate whether information sets differ by educational background. In a second step we differentiate between students with and without intentions to enroll, showing that information sets are related to students' enrollment intention. Note first, that intended college enrollment in our sample is around 13 percentage points lower for students from nonacademic compared to students from academic backgrounds.

Table 2: Lack and relevance of information (pre-treatment)

\begin{tabular}{|c|c|c|c|c|}
\hline & \multicolumn{2}{|c|}{ By edu.backgr. } & \multicolumn{2}{|c|}{ By intended coll. enrollment } \\
\hline & Academics & $\begin{array}{l}\text { Non-academics } \\
\text { (Difference) }\end{array}$ & $\begin{array}{c}\text { No } \\
\text { Intention }\end{array}$ & $\begin{array}{l}\text { Intention } \\
\text { (Difference) }\end{array}$ \\
\hline Int. college enrollment & 0.864 & $-0.132^{* * *}$ & & \\
\hline \multicolumn{5}{|l|}{ Info.source } \\
\hline Info. source: Parents/Family & 0.949 & $-0.076 * * *$ & 0.878 & 0.030 \\
\hline Parents/Family helpful as info. source (1-5) & 3.935 & $-0.389^{* * *}$ & 3.658 & 0.055 \\
\hline \multicolumn{5}{|l|}{ Costs } \\
\hline Feeling well informed about uni.edu. & 0.377 & $-0.046^{*}$ & 0.227 & $0.154^{* * *}$ \\
\hline Problem:obtaining info & 0.248 & 0.034 & 0.271 & -0.003 \\
\hline Not/hardly dealt with fin.poss. & 0.458 & 0.027 & 0.614 & $-0.176^{* * *}$ \\
\hline No scholarships known & 0.281 & $0.085^{* * *}$ & & \\
\hline Perceived cost burden high & 0.280 & $0.205^{* * *}$ & 0.526 & $-0.152^{* * *}$ \\
\hline \multicolumn{5}{|l|}{ Returns } \\
\hline Unemp.risk smaller & 0.428 & -0.043 & 0.293 & $0.139 * * *$ \\
\hline Prosp. for well paid job higher & 0.706 & 0.011 & 0.573 & $0.180^{* * *}$ \\
\hline Rel.inc.premium (B.A./Voc.degr.) & 1.493 & 0.040 & 1.497 & 0.026 \\
\hline Life time inc. higher & 0.641 & 0.009 & 0.582 & $0.082^{* *}$ \\
\hline $\mathrm{N}$ & 375 & 613 & 215 & 773 \\
\hline
\end{tabular}

Notes: This table presents means and mean differences based on a two-sided t-test. Standard errors in parentheses are clustered at the school level. The figures show the share of students whose answers are in accordance with the statements listed in the left column. Source: Best Up, wave 1. * $p<0.10, * * p<0.05, * * * p<0.01$.

Moreover, 95 percent of students from an academic background rely on their parents and family for information and rate this information on average as rather helpful. In contrast, only 88 percent of students from a non-academic background rely on their parents and perceive family as an information source as less helpful 23 Comparing the information set by educational background (column 1 and 2 of Table 2) reveals that students from a non-academic family background feel less informed about university education than their academic peers. ${ }^{24}$ However, the difference of almost five percentage points is not significant.

Students from non-academic backgrounds seem also more likely to have problems in obtaining

\footnotetext{
${ }^{23}$ Table A.3 in the Appendix displays further differences in used sources of information by students educational background. Apart from drawing less on parents and family to obtain information, students from a non-academic background more often draw on job information centers provided by the state-run Agency for Employment. Irrespective of their educational background, students mostly rely on information provided on the Internet. Additionally, the table shows differences by educational background for other characteristics that might influence intended college enrollment.

${ }^{24}$ This is based on the question of whether students feel well informed about the general rules and possibilities of university.
} 
information about post-secondary education and are less likely to have dealt with possibilities to finance university attendance. However, the latter two differences are not statistically significant. Approximately 37 percent of students with a non-academic family background are unaware of any scholarships, as opposed to 28 percent of students with an academic family background. Knowledge about scholarships would be particularly important for students who fall just above the threshold for being eligible to receive student aid, i.e.BAföG'. The perception of "how difficult financing university education" is also varies significantly by educational background. Almost half of the students from a non-academic family background state that bearing the costs during university education is very difficult or mostly difficult.

Columns 3 and 4 of Table 2 show that part of the described differences are linked to students' intention to enroll in college.25 Most of the differences have the expected signs, implying that the level of information is important in forming educational expectations. Students who intend to seek university education are significantly more likely to feel well-informed about university education compared to students who do not intend to enroll in college, pointing towards a relationship between information sets and post-secondary aspirations. Students who have at least partly dealt with financing possibilities and do not perceive the financial burden of university education as high or very high are also more likely to aspire to university education. Note that the subjective income premium associated with a higher degree is not significantly correlated with educational aspirations. However, perceiving the unemployment risk to be lower, the prospects of finding a well-paid job and life time earnings to be higher with a university degree compared to a vocational degree is highly correlated with students' intended college enrollment. Thus, a lack of information on returns to tertiary education potentially affects enrollment in university. Interestingly, the differences in the information set by intended college enrollment, i.e. columns 3 and 4 in Table 2 are mostly driven by students from non-academic backgrounds (see Table A.4 in the Appendix). If we look at the sub-groups of students from academic and non-academic backgrounds and differentiate them by intended college enrollment, these differences are stronger for students from non-academic backgrounds. This suggests that information is more important in forming an intention to enroll in college for students from non-academic than from academic backgrounds.

\subsection{Treatment effect on intended college enrollment}

Table 3 shows the treatment effect of the information intervention on intended college enrollment based on Equation 1 and 2 for the whole sample as well as separately by educational background. Looking at the whole sample first, we find a positive but insignificant effect of the information intervention on intended college enrollment. However, this result masks considerable effect heterogeneities by educational background. Splitting the sample and considering students from non-academic and academic backgrounds separately, we find that, based on mean comparison, the information intervention causes an increase in intended college enrollment of 5.9 percentage points for students from a non-academic family background. Given students'

\footnotetext{
${ }^{25}$ The columns in Table 2 are not mutually exclusive, but if we look at the sub-group of students intending to enroll in college and differentiate them by educational background, the differences found in column 1 and 2 remain similar.
} 
baseline intention, this increase corresponds to an overall boost in the share of students with a non-academic family background intending to go to university of 8.5 percent. The effect differs to a large extent for students from an academic family background. For these students the treatment leads to a decrease in intended college enrollment by 5.7 percentage points or by 6.7 percent respectively. Adding further control variables only marginally changes our estimates but increases precision in the subsample of students from an academic background.

Table 3: Treatment effect on intended college enrollment

\begin{tabular}{|c|c|c|c|c|c|c|}
\hline \multirow[b]{2}{*}{$\begin{array}{l}\text { Mean comparison } \\
\left(\text { contr.for } y_{t 0}\right)\end{array}$} & \multicolumn{2}{|c|}{ All } & \multicolumn{2}{|c|}{ Non-academics } & \multicolumn{2}{|c|}{ Academics } \\
\hline & $\begin{array}{c}0.0156 \\
(0.0240)\end{array}$ & $\begin{array}{c}0.0118 \\
(0.0240)\end{array}$ & $\begin{array}{l}0.0588^{*} \\
(0.0296)\end{array}$ & $\begin{array}{l}0.0577^{*} \\
(0.0298)\end{array}$ & $\begin{array}{l}-0.0565^{*} \\
(0.0303)\end{array}$ & $\begin{array}{c}-0.0601^{* *} \\
(0.0287)\end{array}$ \\
\hline Change & $\begin{array}{c}0.0329 \\
(0.0221)\end{array}$ & $\begin{array}{c}0.0288 \\
(0.0246)\end{array}$ & $\begin{array}{c}0.0825^{* *} \\
(0.0359)\end{array}$ & $\begin{array}{r}0.0849 * * \\
(0.0356)\end{array}$ & $\begin{array}{l}-0.0499^{*} \\
(0.0274)\end{array}$ & $\begin{array}{c}-0.0573^{* *} \\
(0.0268)\end{array}$ \\
\hline $\begin{array}{l}\text { Controls } \\
\mathrm{N}\end{array}$ & $\begin{array}{ll}\text { No } & \\
& 9\end{array}$ & 8 Yes & No & 3 Yes & No & Yes \\
\hline
\end{tabular}

Notes: Control variables include school type, age, gender, migration background, standardized math and German grades as well as two measures for cognitive skills measured by a verbal and a matrix test. When comparing means we additionally control for pre-treatment intentions to enroll in college. Standard errors in parentheses are clustered at the school level. Source: Best Up, wave 1 and $2 .{ }^{*} p<0.10, * * p<0.05, * * * p<0.01$.

At the bottom of Table 3 we report estimates of our preferred specification, in which we compare the change in intended college enrollment across treatment status, i.e. estimates of Equation 2. Fully accounting for pre-treatment differences in intended college enrollment, the effect of the information intervention even increases for students from non-academic backgrounds, amounting to 8.3 percentage points along with an increase in statistical significance. For students from academic backgrounds both specifications yield similar estimates. Again, adding control variables to this specification does not alter our results with respect to effect size but increases statistical significance of our estimates for students from academic backgrounds.

Our results further imply that the information treatment successfully decreased the gap in students' intended college enrollment by educational background. Prior treatment the gap in intended college enrollment by educational background was 16 percentage points in the treatment and 12 percentage points in the control group. By increasing the intention to enroll in college for students from non-academic and decreasing enrollment intentions for students from academic backgrounds, the information workshop reduces the gap in the treatment group by 11 percentage points, while the gap even widens in the control group (by 2 percentage points).

The fact that students from different educational backgrounds respond in opposite direction to the information treatment suggests that information sets of students may indeed be biased towards the type of education that prevails in their environment. Where students from nonacademic backgrounds may lack information about university education, students from academic backgrounds may have an information deficit about options other than university education. Prior to the intervention these students may just emulate individuals with a similar background thinking that they made optimal choices (Manski, 1993ab; Bifulco, Fletcher, Oh, and Ross, 2014). Students, however, should be able to choose the post-secondary education that best fits their interests and potential. Regardless of higher labor market returns, university education 
may not be the optimal choice for every student. As such, students who decrease their intention to enroll in college after treatment may indeed be better off pursuing a vocational degree. This argument is substantiated by our finding that the negative treatment effect for students from academic backgrounds is solely driven by students who are less able ${ }^{26}$ In contrast, for students from a non-academic background we do not find significantly different effects of the information intervention for students with different levels of skills.

\subsection{Adjustments to pre-treatment educational plans}

In order to investigate the effect of the information intervention a bit further, we disaggregate the change in intended college enrollment into three further outcomes. Between periods, students can either adjust their educational expectations upwards, downwards or stay with their educational plans. We define upward adjustment as a binary variable equal to one if a student had pre-treatment no intention to enroll in college and changed her intention towards pursuing a college education post-treatment, and zero otherwise. Similarly, downward adjustment indicates students who change from having an enrollment intention (pre-treatment) to having no intention anymore (post-treatment). Finally, if students maintain their educational intentions, either to enroll in college or to obtain a vocational degree, we refer to it as stable intentions. This disaggregation is particularly interesting for students from non-academic backgrounds as it has been shown in the literature that these students have more difficulties in forming and maintaining high educational expectations (see e.g. the literature reviewed in Engle, 2008). The formation and stabilization of high educational expectations crucially depend on the level of encouragement students receive in their environment. Students from a non-academic family background generally receive less encouragement and, consequently, are less likely to maintain their educational expectations compared to students from an academic family background. Being informed on earnings premium and possibilities to finance studies by our information intervention, might have also acted as such an encouragement.

We estimate the effect of the information intervention on these three outcomes separately.

Table 4: Adjustments to pre-treatment intentions

\begin{tabular}{|c|c|c|}
\hline & Non-academics & Academics \\
\hline (1) Upward adjustment & $\begin{array}{c}0.0528^{* *} \\
(0.0241)\end{array}$ & $\begin{array}{c}-0.0284^{*} \\
(0.0145)\end{array}$ \\
\hline (2) Downward adjustment & $\begin{array}{l}-0.0297 \\
(0.0240)\end{array}$ & $\begin{array}{c}0.0215 \\
(0.0214)\end{array}$ \\
\hline (3) Stable intention & $\begin{array}{l}-0.0231 \\
(0.0321)\end{array}$ & $\begin{array}{c}0.0070 \\
(0.0241)\end{array}$ \\
\hline $\mathrm{N}$ & 613 & 375 \\
\hline
\end{tabular}

\footnotetext{
${ }^{26}$ We define less able as scoring below the median in the combined cognition tests conducted pre-treatment. See Table A.5 in the Appendix. These results must interpreted with caution, as sample sizes decrease, if subgroups are further differentiated by students' skill level.
} 
The results are presented in Table 4 . For students from non-academic backgrounds the effect of the information intervention can indeed be attributed to a significant upward adjustment in intended college enrollment. The effect on downward adjustment suggests that the information treatment might have also worked through preventing a downward adjustment. However, the effect is too small to turn out significant. In contrast, the negative effect for students from academic backgrounds is rather caused by averting an upward adjustment than by provoking a downward adjustment in intended college enrollment.

\section{Robustness tests}

In this section we perform various robustness tests and investigate how sensitive our estimates are to different specifications. A summary of the sensitivity analyses is shown in Table 5 , where the first row shows the main estimates as a reference point.

Accounting for attrition. Attrition is a common problem in RCTs that rely on survey data to measure the outcome of interest. Generally, attrition poses a threat to the estimation of the treatment effect only if there are non-random differences between treatment and control groups. This may result in biased estimates of the treatment effect. As outlined in section 3 differential attrition is of no concern for our estimations. However, even if there is no differential attrition between treatment and control group, we might still be worried if certain types of students are over- or underrepresented in the analyzed sample and treatment effects vary for these groups. For example, if the information intervention is more (less) effective for underrepresented groups, our estimates will be biased downward (upward). It is well known that individuals with certain characteristics are more likely to respond to surveys than others. Comparing attritors and non-attritors in our sample, shows that students who are younger, female, have no migration background, and have higher math grades, German grades, or have higher scores on cognitive measures are more likely to participate in the post-treatment survey. In order to investigate how this affects our estimates, we predict the subgroup-specific probability to participate in the posttreatment survey and rerun our estimation using the inverse of these probabilities as sampling weights. To predict post-treatment participation we use the same set of covariates as in our main specifications as well as pre-treatment intentions to enroll in college. Additionally, we include a binary variable indicating whether we have valid data on the contact information (email, address, phone) that was used to contact students for the post-treatment survey and collected in the pretreatment survey. Using inverse probability weights slightly decreases our point estimate for students from non-academic backgrounds, whereas it increases (in absolute values) for students from academic backgrounds. Nevertheless, effect size and statistical significance remain.

Accounting for covariate imbalance. In Table 1 we showed the covariate balance for the sample that we use for our analysis as well as for the subgroups by educational background. Most of the covariate differences are insignificant. However, irrespective of the significance of these differences, the size of some of the differences may trigger concerns about the comparability of treatment and control group students. In order to increase the similarity of treated and control group students we rerun our estimation using entropy balancing weights (Hainmueller, 2012, Hainmueller and $\mathrm{Xu}, 2013$ ). Entropy balancing weights reweigh control group students such that a set of pre-specified moment conditions are equal across treatment status. This procedure 
selects the set of weights that satisfies the pre-specified moment conditions but remains as close as possible to uniform weights (Hainmueller, 2012). In our estimation we require the first moment of all variables included as controls to be the same in the control group as in the treatment group. As shown in Table 5 our results for students from non-academic backgrounds are largely unaffected. For students from academic backgrounds we again find a higher negative treatment effect but the change is less than one percentage point.

Table 5: Sensitivity Analysis

\begin{tabular}{|c|c|c|c|c|}
\hline & \multicolumn{2}{|c|}{ Non-academics } & \multicolumn{2}{|c|}{ Academics } \\
\hline (1) Main & $\begin{array}{c}0.0849 * * \\
(0.0356)\end{array}$ & {$[613]$} & $\begin{array}{c}-0.0573^{* *} \\
(0.0268)\end{array}$ & {$[375]$} \\
\hline (2) Inverse prob.weighting & $\begin{array}{c}0.0791^{* *} \\
(0.0380)\end{array}$ & {$[613]$} & $\begin{array}{c}-0.0808^{* *} \\
(0.0362)\end{array}$ & {$[373]$} \\
\hline (3) Entropy balancing & $\begin{array}{c}0.0810^{* *} \\
(0.0337)\end{array}$ & {$[613]$} & $\begin{array}{c}-0.0664^{* *} \\
(0.0297)\end{array}$ & {$[375]$} \\
\hline (4) w/o low response schools & $\begin{array}{c}0.0828^{* *} \\
(0.0359)\end{array}$ & {$[559]$} & $\begin{array}{c}-0.0558^{*} \\
(0.0291)\end{array}$ & {$[324]$} \\
\hline (5) w/o potential 'spill-over schools' & $\begin{array}{c}0.0777^{* *} \\
(0.0302)\end{array}$ & {$[532]$} & $\begin{array}{c}-0.0715^{* * *} \\
(0.0242)\end{array}$ & {$[352]$} \\
\hline (6) Two Stage Least Squares & $\begin{array}{c}0.0856^{* *} \\
(0.0381)\end{array}$ & {$[613]$} & $\begin{array}{c}-0.0509^{*} \\
(0.0289)\end{array}$ & {$[375]$} \\
\hline (7) Strict def. on edu.backgr. & $\begin{array}{c}0.0905^{* *} \\
(0.0343)\end{array}$ & {$[567]$} & $\begin{array}{c}-0.0578^{* *} \\
(0.0238)\end{array}$ & {$[367]$} \\
\hline
\end{tabular}

Notes: All estimates are based on Equation (1) and include the following control variables: school type, age, gender, migration background, standardized math and German grades as well as two measures for brackets. Standard errors in parentheses are clustered at the school level. Source: Best Up, wave 1 and 2. ${ }^{*} p<0.10,{ }^{* *} p<0.05, * * * p<0.01$.

Discarding selected schools. In Table 5 we further investigate how sensitive our results are to considering specifics of the project setup, i.e. student level participation and geographical proximity of schools.

First, although the information workshop as well as the pre-treatment survey were conducted during school hours, participation for students was still on a voluntary basis due to strict data protection regulations in Germany. As a result, we observe school-level differences in response rates to the pre-treatment survey. If students' decision to participate is correlated with intended college enrollment, our results will be biased. Thus, to limit the possibility that our results are driven by selection into (student-level) survey participation, we drop those schools with the five lowest school-level response rates from our sample. As shown in row 4, the change in point estimates is minimal.

And second, given that the project's focus was to conduct its RCT in low-educated districts in Berlin, one concern may be that students of treatment schools potentially inform control school students of the information workshop leading to spill-over effects. We rerun our estimations excluding all students from control schools that are close, i.e. within a two kilometer radius of 
a treatment school. For students from non-academic backgrounds this yields almost no change; for students from academic backgrounds the estimate increases in absolute values implying a downward bias (in absolute values) of our main estimate of 1.4 percentage points.

Dealing with non-compliance. One school of the treatment group did not receive the information workshop due to a mis-communication between the headmaster and its teaching staff. It was, however, possible to survey at least some of the students in this school. For our estimations, as presented in section 5, we assigned this school to the control group. In order to diffuse any concerns about this reclassification of a school, we estimate the effect of the information intervention via a two stage least squares approach. We use the original classification of schools into treatment and control group to predict actual treatment status, i.e. whether a school actually received the information workshop, in the first stage and treat the predicted values as our treatment indicator in the second stage. We use the same set of control variables in both stages. Compared to our main specification, the changes in point estimates are only marginal.

Defining educational background. To cope with missing information on students' educational background we made several assumptions in order to approximate students' background (described in section 3), thereby minimizing the loss of observations. We investigate here whether a potential misclassification of students affects our estimates. We, therefore, restrict our sample to students for whom we have complete information on parental education. This approach does changes our point estimates and significance levels only minimally.

Overall, our sensitivity analysis, as summarized in Table 5. confirms our results. The estimates do not differ significantly from our preferred estimation as presented in Table 3 . However, point estimates for students from academic backgrounds vary slightly more given the smaller sample size.

\section{Conclusion}

This paper contributes to the growing economic literature on the effect of information provision on educational decisions. We present results using data from a randomized controlled trial in Germany. Students in randomly selected schools were treated with information about returns to tertiary education as well as different funding possibilities for university education. Students seem to comprehend the information they are given. We find that the provision of information increases intended college enrollment for students from non-academic backgrounds, while it leads students from academic family backgrounds to lower their intention to enroll. The fact that we find a significant effect on intended college enrollment shows that pre-treatment plans do not reflect optimal choices and that students do indeed lack information. If students' intentions were already optimal prior to treatment, receiving information should have no effect. In contrast to the study by Kerr, Pekkarinen, Sarvimäki, and Uusitalo (2015), our results indicate that providing (general) information has the potential to impact educational choices. One explanation for the differing results, despite the similar context, may be that the general educational decision, i.e. students' choice between university education and an alternative, may be more responsive to overall information than major-specific choices in university. Another possibility may be that teachers/counselors in the RCT by Kerr, Pekkarinen, Sarvimäki, and 
Uusitalo (2015) differ in their presentation of the information materials and thus no significant treatment effect can be identified.

A particularly interesting result of our study is that providing information about postsecondary educational choices may result in better matches. For students who decrease their intention to enroll in college after treatment, the information intervention may have reminded them of an attractive alternative path, namely vocational education. The treatment may have led these students to re-consider their options after graduation instead of blindly following the expectations of their surroundings.

Although we find a differential causal effect of information provision, the question which specific information triggered this result, is less clear. Further research is needed to obtain a better understanding of what particular type of information helps students to find the best match, i.e. encourages students from non-academic family backgrounds to pursue university education and at the same time, raises the awareness for alternatives to university education for students from academic backgrounds.

The gap in educational attainment by family background is mostly discussed from the angle of inequality of opportunities, whereas the loss of efficiency through a mismatch of skills is too often neglected. However, especially in countries with a shrinking labor force, the efficient use of human capital resources gains importance. The findings of this paper show that educational inequality - measured by the differences in students' intended college enrollment by parental educational - can be reduced by providing students with relevant information, while simultaneously improving educational matches. A tailored information workshop may indeed be an appropriate and inexpensive policy tool to narrow the gap in take up of tertiary education. 


\section{References}

Ajzen, I. (1985): "From Intentions to Actions: A Theory of Planned Behavior," in Action Control, ed. by J. Kuhl, and J. Beckmann, SSSP Springer Series in Social Psychology, pp. 11-39. Springer Berlin Heidelberg.

(1991): "The theory of planned behavior," Organizational Behavior and Human Decision Processes, 50(2), 179 - 211, Theories of Cognitive Self-Regulation.

Allison, P. D. (1990): "Change Scores as Dependent Variables in Regression Analysis," Sociological Methodology, 20, 93-114.

Becker, R., And A. Hecken (2008): "Warum werden Arbeiterkinder vom Studium an Universitäten abgelenkt? Eine empirische Überprüfung der "Ablenkungsthese" von Müller und Pollak (2007) und ihrer Erweiterung durch Hillmert und Jacob (2003)," Kölner Zeitschrift für Soziologie und Sozialpsychologie, 60(1), 3-29.

Bettinger, E. P., B. T. Long, P. Oreopoulos, and L. Sanbonmatsu (2012): "The Role of Application Assistance and Information in College Decisions: Results from the H\&R Block FAFSA Experiment," The Quarterly Journal of Economics, 127(3), 1205-1242.

Bifulco, R., J. M. Fletcher, S. J. Oh, and S. L. Ross (2014): "Do high school peers have persistent effects on college attainment and other life outcomes?," Labour Economics, 29, 83 $-90$.

Bildungsberichterstattung, A. (2014): "Bildung in Deutschland 2014," Ein indikatorengestützter Bericht mit einer Analyse zur Bildung von Menschen mit Behinderungen.

Booij, A. S., E. Leuven, and H. Oosterbeek (2012): "The role of information in the take-up of student loans," Economics of Education Review, 31(1), 33-44.

Dinkelman, T., and C. Martínez (2014): "Investing in Schooling In Chile: The Role of Information about Financial Aid for Higher Education," Review of Economics and Statistics, 96(2), 244-257.

Dynarski, S. (2002): "The Behavioral and Distributional Implications of Aid for College," The American Economic Review, 92(2), 279-285.

Engle, J. (2008): "Postsecondary Access and Success for First-Generation College Students," in American Academic Volume Three, pp. 25-48. Pell Institute for the Study of Opportunity in Higher Education, Boulder: Westview Press.

Fishbein, M., And I. AJzen (1975): Belief, Attitude, Intention, and Behavior: An Introduction to Theory and Research. Reading, MA: Addison-Wesley.

Hainmueller, J. (2012): "Entropy Balancing for Causal Effects: A Multivariate Reweighting Method to Produce Balanced Samples in Observational Studies," Political Analysis, 20(1), 25-46. 
Hainmueller, J., And Y. Xu (2013): "Ebalance: A Stata Package for Entropy Balancing," Journal of Statistical Software, 54(7), 1-18.

Herber, S. P. (2015): "The Role of Information in the Application for Merit-Based Scholarships: Evidence from a Randomized Field Experiment," BERG Working Paper 95, University of Bamberg.

Hoxby, C., And S. Turner (2014): "Expanding College Opportunities for High-Achieving, Low Income Students," Discussion Paper No. 12-014, Stanford Institute for Economic Policy Research, SIEPR Discussion Paper No. 12-014.

IACus, S., G. King, and G. Porro (2009): "CEM: Software for Coarsened Exact Matching," Journal of Statistical Software, 30(9), 1-27.

Jensen, R. (2010): "The (Perceived) Returns to Education and the Demand for Schooling," Quarterly Journal of Economics, 125(2), 515-548.

Kerr, S. P., T. Pekkarinen, M. Sarvimäki, and R. Uusitalo (2015): "Post-Secondary Education and Information on Labor Market Prospects: A Randomized Field Experiment," Discussion paper 9372, IZA.

Loyalka, P., Y. Song, J. Wei, W. Zhong, and S. Rozelle (2013): "Information, college decisions and financial aid: Evidence from a cluster-randomzed controlled trial in China," Economics of Education Review, 36, 26-40.

Manski, C. F. (1993a): "Adolescent Econometricians: How Do Youth Infer the Returns to Schooling?," in Studies of Supply and Demand in Higher Education, ed. by C. T. Clotfelter, and M. Rothschild, chap. 2, pp. 43-60. University of Chicago Press.

(1993b): "Dynamic choice in social settings," Journal of Econometrics, 58(1-2), 121136.

McGuigan, M., S. McNally, and G. Wyness (2014): "Student Awareness of Costs and Benefits of Educational Decisions: Effects of an Information Campaign and Media Exposure," IZA Discussion Paper 8596, Institute for the Study of Labor, Bonn.

Middendorff, E., B. Apolinarski, J. Poskowsky, M. Kandulla, and N. Netz (2013): "Die wirtschaftliche und soziale Lage der Studierenden in Deutschland 2012," 20. Sozialerhebung des Deutschen Studentenwerks durchgeführt durch das HIS-Institut für Hochschulforschung.

Nguyen, T. (2008): "Information, Role Models and Perceived Returns to Education: Experimental Evidence from Madagascar," mimeo.

Oreopoulos, P., And R. Dunn (2013): "Information and College Access: Evidence from a Randomized Field Experiment," The Scandinavian Journal of Economics, 115(1), 3-26.

Oxoвy, R. J. (2008): "Skill uncertainty and social inference," Labour Economics, 15(3), 400 405. 
Steiner, V., and K. Wrohlich (2012): "Financial Student Aid and Enrollment in Higher Education: New Evidence from Germany," The Scandinavian Journal of Economics, 114(1), $124-147$. 


\section{Appendix}

Table A.1: Covariate balance by treatment status

\begin{tabular}{lcc}
\hline \hline & \multicolumn{2}{c}{ Full sample } \\
\cline { 2 - 3 } & $\begin{array}{c}\text { Control } \\
\text { Group Mean }\end{array}$ & $\begin{array}{c}\text { Treatment } \\
\text { Group Diff. }\end{array}$ \\
\hline Int. college enrollment & 0.777 & -0.029 \\
Individual characteristics & 18.677 & -0.051 \\
Age & 0.571 & -0.009 \\
Female & 0.515 & 0.046 \\
Migration background & 0.615 & 0.003 \\
Non-academic fam.backgr. & & \\
Performance and skills & 8.580 & -0.134 \\
German Grade & 7.714 & 0.146 \\
Math Grade & 9.492 & 0.278 \\
Cognition test (verbal) & 10.706 & 0.142 \\
Cognition test (figural) & & \\
School type & 0.297 & -0.035 \\
School type I (Gym.) & 0.366 & 0.044 \\
School type II (Gesamtschule) & 0.336 & -0.009 \\
School typ III (beruf.Gym.) & & \\
Perceived returns & 0.392 & -0.007 \\
Unemp.risk smaller & 0.702 & 0.002 \\
Prosp. for well paid job higher & 1.546 & -0.003 \\
Rel.inc.premium (B.A./Voc.degr.) & 0.623 & -0.001 \\
Life time inc. higher & 1086 & 492 \\
\hline N (total) & \multicolumn{2}{c}{1578} \\
N (tota & \\
\hline
\end{tabular}

Notes: This table presents control group means and treatment-control differences based on a two-sided t-test. Standard errors are clustered at the schoo level. Source: Best Up, wave $1 .{ }^{*} p<0.1,{ }^{* *} p<0.05,{ }^{* * *} p<0.01$.

Table A.2: Treatment effect on perceived labor market returns

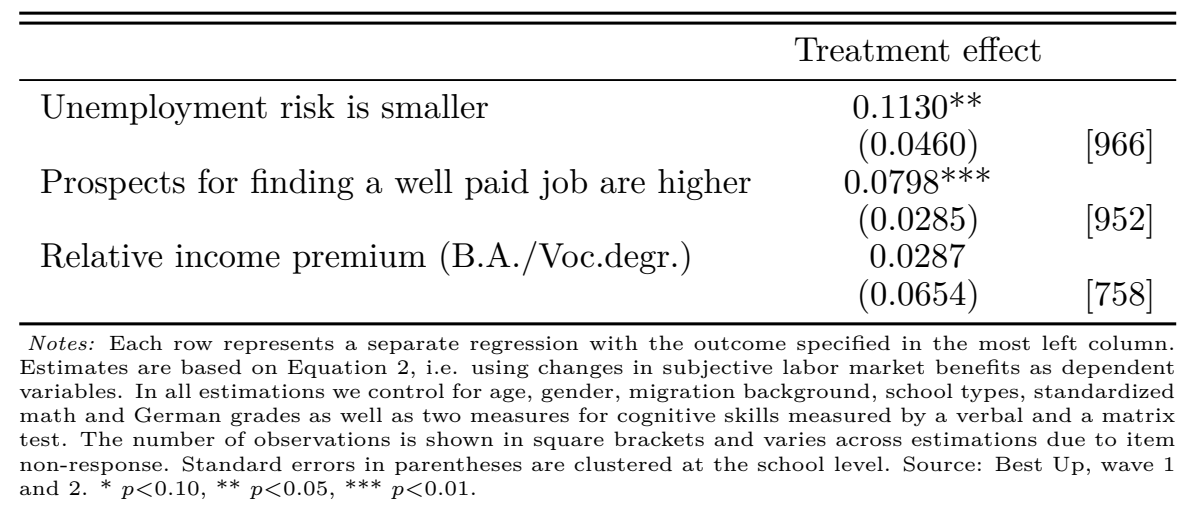


Table A.3: Descriptive statistics

\begin{tabular}{|c|c|c|c|}
\hline & $\begin{array}{l}\text { Non-academic } \\
\text { backgr. }\end{array}$ & $\begin{array}{l}\text { Academic } \\
\text { backgr. }\end{array}$ & Difference \\
\hline \multicolumn{4}{|l|}{ Socio-demographic characteristics } \\
\hline Age & 18.662 & 18.363 & $0.300^{* * *}$ \\
\hline Female & 0.617 & 0.552 & $0.065^{*}$ \\
\hline Migration background & 0.522 & 0.419 & $0.103^{* *}$ \\
\hline \multicolumn{4}{|l|}{ Performance and Skills } \\
\hline German Grade & 8.467 & 9.144 & $-0.677^{* * *}$ \\
\hline Math Grade & 7.965 & 8.450 & $-0.485^{*}$ \\
\hline Cognition test (verbal) & 9.460 & 10.605 & $-1.145^{* * *}$ \\
\hline Cognition test (figural) & 10.917 & 11.312 & $-0.395^{*}$ \\
\hline \multicolumn{4}{|l|}{ School types } \\
\hline School type I (Gym.) & 0.295 & 0.325 & -0.030 \\
\hline School type II (Gesamtschule) & 0.374 & 0.365 & 0.008 \\
\hline School typ III (berufl.Gym.) & 0.331 & 0.309 & 0.022 \\
\hline \multicolumn{4}{|l|}{ Job choice values } \\
\hline Social orient. & -0.005 & -0.088 & 0.084 \\
\hline Extrinsic orient. & 0.034 & -0.164 & $0.198 * *$ \\
\hline Intrinsic orient. & -0.048 & 0.131 & $-0.179 * *$ \\
\hline External orient. & 0.064 & -0.128 & $0.193^{* *}$ \\
\hline \multicolumn{4}{|l|}{ Information sources } \\
\hline Internet & 95.402 & 94.879 & 0.524 \\
\hline Parents/Family & 87.273 & 94.879 & $-7.606^{* * *}$ \\
\hline Friends & 89.256 & 88.679 & 0.577 \\
\hline Central study counseling & 36.913 & 38.859 & -1.946 \\
\hline Job info.center/Emp.agency & 60.738 & 52.162 & $8.576^{* *}$ \\
\hline Int. college enrollment & 0.732 & 0.864 & $-0.132^{* * *}$ \\
\hline $\mathrm{N}$ & 613 & 375 & \\
\hline
\end{tabular}

Table A.4: Relevance of information by educational background

\begin{tabular}{|c|c|c|c|c|}
\hline & \multicolumn{2}{|c|}{ Non-academic backgr. } & \multicolumn{2}{|c|}{ Academic backgr. } \\
\hline & $\begin{array}{c}\text { No } \\
\text { Intention }\end{array}$ & $\begin{array}{l}\text { Intention to enroll } \\
\text { (Difference) }\end{array}$ & $\begin{array}{c}\text { No } \\
\text { Intention }\end{array}$ & $\begin{array}{l}\text { Intention to enroll } \\
\text { (Difference) }\end{array}$ \\
\hline \multicolumn{5}{|l|}{ Info.source } \\
\hline Info. source: Parents/Family & 0.870 & 0.003 & 0.902 & $0.054 *$ \\
\hline Parents/Family helpful as info. source (1-5) & 3.674 & -0.175 & 3.609 & $0.375^{*}$ \\
\hline \multicolumn{5}{|l|}{ Costs } \\
\hline Feeling well informed about uni.edu. & 0.236 & $0.129^{* * *}$ & 0.200 & $0.204^{* *}$ \\
\hline Problem:obtaining info & 0.264 & 0.025 & 0.294 & -0.053 \\
\hline Not/hardly dealt with fin.poss. & 0.608 & $-0.165^{* * *}$ & 0.636 & $-0.203^{* *}$ \\
\hline Perceived cost burden high & 0.593 & $-0.148^{* * *}$ & 0.314 & -0.040 \\
\hline \multicolumn{5}{|l|}{ Returns } \\
\hline Unemp.risk smaller & 0.274 & $0.152^{* * *}$ & 0.353 & 0.087 \\
\hline Prosp. for well paid job higher & 0.571 & $0.201 * * *$ & 0.580 & $0.147^{*}$ \\
\hline Rel.inc.premium (B.A./Voc.degr.) & 1.531 & 0.002 & 1.392 & 0.117 \\
\hline Life time inc. higher & 0.580 & $0.095^{* *}$ & 0.588 & 0.061 \\
\hline $\mathrm{N}$ & 164 & 449 & 51 & 324 \\
\hline
\end{tabular}


Table A.5: Differential treatment effect by skill level

\begin{tabular}{|c|c|c|}
\hline & Non-academics & Academics \\
\hline Treatment $*$ More able & $\begin{array}{l}-0.0456 \\
(0.0606)\end{array}$ & $\begin{array}{l}0.1237^{*} \\
(0.0613)\end{array}$ \\
\hline Treatment & $\begin{array}{l}0.1097^{*} \\
(0.0585)\end{array}$ & $\begin{array}{c}-0.1104^{* * *} \\
(0.0275)\end{array}$ \\
\hline More able & $\begin{array}{c}0.0224 \\
(0.0625) \\
\end{array}$ & $\begin{array}{c}0.0769 \\
(0.0802) \\
\end{array}$ \\
\hline $\mathrm{N}$ & 613 & 375 \\
\hline $\begin{array}{l}\text { otes: Estimates are based on } \\
\text { eraction term between the tre } \\
\text { ting whether a student scores } \\
\text { ts. In all estimations we con } \\
\text { oool types, standardized math } \\
\text { cognitive skills measured by } \\
\text { parentheses are clustered at } \\
{ }^{*} p<0.10, * * p<0.05,{ }^{* * *} p<0\end{array}$ & $\begin{array}{l}\text { on } 2 \text { where we ad } \\
\text { t indicator and a } \\
\text { the median in the } \\
\text { or age, gender, } \mathrm{m} \\
\text { yerman grades as } \\
\text { al and a matrix } \\
\text { ool level. Source: }\end{array}$ & $\begin{array}{l}\text { aally include ar } \\
\text { y variable indi } \\
\text { bined cognition } \\
\text { on background } \\
\text { on two measure } \\
\text { Standard error } \\
\text { Up, wave } 1 \text { and }\end{array}$ \\
\hline
\end{tabular}

